\section{Differential effects of therapeutic complement inhibitors on serum bactericidal activity against non-groupable meningococcal isolates recovered from patients treated with eculizumab}

Eculizumab is licensed for the treatment of paroxysmal nocturnal hemoglobinuria, atypical hemolytic uremic syndrome, and generalized myasthenia gravis. By blocking C5, eculizumab inhibits meningococcal serum bactericidal activity (SBA), leaving patients at an approximately 2000-fold higher risk of meningococcal disease than the general population. ${ }^{1}$ This increased risk includes invasive disease caused by unencapsulated (non-groupable, NG) strains, ${ }^{1,2}$ which rarely cause invasive disease in normal hosts.

$\mathrm{ACH}-4471^{4}$ targets complement factor $\mathrm{D}$ in the alternative pathway (Online Supplementary Figure S1), and is being developed to treat paroxysmal nocturnal hemoglobinuria and C3 glomerulopathy. Since the terminal pathway remains intact, SBA can occur in the presence of ACH-4471 via the classical and lectin pathways (Online Supplementary Figure S1). In a previous study, eculizumab completely blocked whole blood opsonophagocytic killing of encapsulated serogroup $B$ and $C$ meningococcal strains while blocking factor $\mathrm{D}$ with $\mathrm{ACH}-4471$ gave less impairment. ${ }^{5}$ Here we describe 18 cases of invasive meningococcal disease in eculizumab recipients reported to the US Centers for Disease Control and Prevention between January 2008 and July 2018 (Online Supplementary Table S1), and the effect of eculizumab and $\mathrm{ACH}-4471$ on SBA against NG meningococcal isolates recovered from eight of these patients.

The indications for eculizumab were paroxysmal nocturnal hemoglobinuria in 12 patients, atypical hemolytic uremic syndrome in five, and neuromyelitis optica (Devic disease) in one. Information on antibiotic prophylaxis was available for 14 patients: two (cases 11 and 18) were receiving penicillin at the time of meningococcal disease onset (Online Supplementary Table S1). The small number of patients in the present series receiving prophylactic antibiotics likely reflected lack of an official recommendation in the USA on routine use of antibiotic prophylaxis in this population.

The susceptibility of the isolates to penicillin was measured by reference broth microdilution. ${ }^{6}$ Isolates from five cases, including both recipients of prophylaxis with the antibiotic, showed intermediate penicillin sensitivity (cases 10, 11, 16, 17 and 18) and one more isolate was penicillin-resistant (case 12, Online Supplementary Table S1).

Capsular serogroups were evaluated by slide agglutination, whole genome sequencing and/or polymerase chain reaction. ${ }^{7}$ Thirteen of the 17 cases $(76 \%)$ with a clinical sample or an isolate available for testing were caused by strains that were NG phenotypically $(n=12$, Table 1$)$ or, for one case where only a clinical specimen was available, by polymerase chain reaction (Table 1). The remaining four were caused by encapsulated serogroup Y isolates (Online Supplementary Table S1). All but one of the NG isolates (case 11, C backbone) showed evidence of disrupted or phase-variable "off" capsular polysaccharide synthesis gene loci (Table 1).

For 16 patients there was documentation of receipt of serogroup A, C, W, Y meningococcal quadrivalent polysaccharide or conjugate vaccine, whereas vaccination status for the remaining two patients was unknown. Of the six eculizumab-treated patients with meningococcal disease onset after June 2015, when serogroup B meningo- coccal vaccine (MenB) was first recommended, ${ }^{8}$ one patient had received one dose of MenB and three had received a complete MenB series (Online Supplementary Table S1).

The MenB-FHbp (Trumenba ${ }^{\circledR}$ ) vaccine contains two recombinant $\mathrm{FHb}$ variants from sub-families $\mathrm{A}$ and $\mathrm{B}$, and MenB-4C (Bexsero ${ }^{\circledR}$ ) contains a sub-family B FHbp and three other meningococcal antigens (recombinant $\mathrm{NHba}$ and NadA, and PorA P1.4 in outer membrane vesicles). These antigens are not limited to capsular group $B$ meningococcal strains. Vaccine antigen expression for the 12 available NG isolates was characterized by flow cytometry using mouse antisera to $\mathrm{FHbp}$, NHba, and NadA as previously described. ${ }^{9}$ All 12 isolates expressed sub-family A or B FHbp and one or two other MenB-4C antigens (Online Supplementary Figure S2A and S2B). None had PorA P1.4.

We measured SBA in sera from eight healthy unvaccinated adults and eight adults vaccinated in previous studies with MenB-4C $(n=4)^{10}$ or MenB-FHbp $(n=4) \cdot{ }^{11}$ Serum selection was based on availability of sufficient volumes for the current studies. One individual, subject 9010, provided sera both before vaccination and 1 month after the MenB-4C dose 2. Sera from the remaining vaccinated subjects were obtained 6 to 12 months after MenB-4C dose 2 or MenB-FHbp dose 3.

The SBA assay used early log phase bacteria incubated with a 1:5 dilution of serum with internal complement preserved. Eculizumab (50 $\mu \mathrm{g} / \mathrm{mL}), \mathrm{ACH}-4471(1 \mu \mathrm{M}),{ }^{4}$ or no inhibitor was added to the reaction and the percent bacterial survival was calculated after incubation at $37^{\circ} \mathrm{C}$ for $60 \mathrm{~min}$.

Against a control serogroup B encapsulated strain (H44/76), all eight unvaccinated sera had SBA titers $<1: 5$ (bacterial survival $>50 \%$ ) (Figure $1 \mathrm{~A}$ ), whereas all eight post-immunization sera had SBA titers $\geq 1: 5$ (Figure 1D, G) $(P=0.0002$, Fisher exact test). Eculizumab completely blocked vaccine-induced SBA (Figure 1D, G). In contrast, $\mathrm{ACH}-4471$ had little or no effect on vaccine-induced SBA against the capsular group $B$ strain (titers $\geq 1: 5$ in all 8 vaccinated subjects) (Figure 1D, G).

In the absence of an added inhibitor, SBA titers were $\geq 1: 5$ against two $\mathrm{NG}$ isolates with a disrupted $\mathrm{B}$ cps locus (isolate CH891) (Figure 1B, E, H) or phase-variable "off" B cps locus (isolate CH892, Figure 1C, F, I) for all 16 unvaccinated or vaccinated subjects. Eculizumab again completely blocked SBA, whereas ACH-4471 had minimal effect.

Similarly, in the absence of a complement inhibitor, three NG isolates with disrupted Y cps loci (Online Supplementary Figure S3), and two NG isolates with capsular null loci (cnl; CH885 and CH896) (Online Supplementary Figure S4) were killed by sera from all 16 unvaccinated or vaccinated adults. Eculizumab completely blocked SBA for all of these isolates and all sera. Blocking the alternative pathway with $\mathrm{ACH}-4471$ had minimal or no effect on SBA against both $\mathrm{cnl}$ isolates and two of the three test isolates with disrupted Y capsular loci. Against the third isolate with a disrupted $\mathrm{Y}$ capsular locus, SBA titers were $<1: 5$ in the presence of ACH-4471 for five of the eight unvaccinated subjects and one of the eight vaccinated subjects (Online Supplementary Figure $S 3 C, F$, and I).

The eighth NG test isolate (CH886), with a disrupted E cps locus, was resistant to killing by sera from two of the eight unvaccinated subjects in the absence of added inhibitor (bacterial survival $>50 \%$; titers $<1: 5$ ) (Figure $2 \mathrm{~A}$, subjects $\mathrm{C}$ and $\mathrm{E})$. The isolate was killed by sera from all 
eight vaccinated subjects (Figure 2B, C). Eculizumab completely inhibited SBA for all sera, and ACH-4471 blocked SBA of all six sera from unvaccinated subjects who had uninhibited titers $\geq 1: 5$ (Figure 2A), and for three of the eight sera from the vaccinated subjects (Figure $2 \mathrm{~B}, \mathrm{C}$ ).

In the experiments described above, the dose of eculizumab was $50 \mu \mathrm{g} / \mathrm{mL}$ and that of $\mathrm{ACH}-4471$ was 1 $\mu \mathrm{M}$, which in previous studies were sufficient to ensure complete blockade of the classical and alternative pathways, respectively. ${ }^{5}$ With the resistant $\mathrm{CH} 886$ isolate, a 5 -fold lower concentration of eculizumab $(10 \mu \mathrm{g} / \mathrm{mL})$ also completely blocked SBA of an unvaccinated serum pool and three representative sera from vaccinated subjects (Online Supplementary Figure S5A). In contrast, decreasing

Table 1. Summary of 12 non-groupable meningococcal case isolates from patients treated with eculizumab.

\begin{tabular}{|c|c|c|c|c|c|c|c|c|}
\hline $\begin{array}{l}\text { Strain } \\
\text { and case } \\
\text { number }\end{array}$ & $\begin{array}{l}\text { CDC strain n./ } \\
\text { year / diagnosis* }\end{array}$ & $\begin{array}{l}\text { Tested } \\
\text { for } \\
\text { SBA§ }\end{array}$ & $\begin{array}{c}\text { Genogroup, } \\
\text { in silico from DNA } \\
\text { sequences of cps loci? } \\
\text { [Accession ID number*] }\end{array}$ & $\begin{array}{c}\text { MLST }^{\dagger} \\
\text { (clonal complex) }\end{array}$ & $\begin{array}{l}\text { PorA } \\
\text { VR }^{\text {Ht }}\end{array}$ & $\begin{array}{l}\text { Neisseria } \\
\text { adhesion A } \\
\text { (NadA) gene } \\
\text { (expression)" }\end{array}$ & $\begin{array}{c}\text { NHha ID } \\
\text { (expression) }\end{array}$ & $\begin{array}{l}\text { FHlop ID } \\
\text { (sub-family/ } \\
\text { expression) }\end{array}$ \\
\hline $\begin{array}{l}\text { CH885 } \\
\text { Case } 2\end{array}$ & $\begin{array}{l}\text { M21130/ } \\
\text { 2010/PNH }\end{array}$ & Yes & $\begin{array}{l}\text { Null locus }(\mathrm{cnl}) \\
{[\text { SAMN10701617] }}\end{array}$ & 823 (198) & $1.17,9$ & Not found & p0010 (33X) & $4(\mathrm{~B} / 41 \mathrm{X})$ \\
\hline $\begin{array}{l}\text { CH886 } \\
\text { Case } 3\end{array}$ & $\begin{array}{l}\text { M22391/ } \\
\text { 2010/NmO }\end{array}$ & Yes & $\begin{array}{c}\text { E backbone: } c s e E \text { disrupted } \\
\text { by insertion element }{ }^{30} \\
\text { [SAMN10701618] }\end{array}$ & $60(60)$ & $1.5,2$ & Not found & p0024 (12X) & $13(\mathrm{~B} / 15 \mathrm{X})$ \\
\hline $\begin{array}{l}\text { CH893 } \\
\text { Case } 6\end{array}$ & $\begin{array}{l}\text { M24108/ } \\
\text { 2011/PNH }\end{array}$ & Yes & $\begin{array}{l}\text { Y backbone: internal stop } \\
\text { in csy [SAMN10701619] }\end{array}$ & $23(23)$ & $1.5-2,10-1$ & 1 Not found & p0007 (15X) & $25(\mathrm{~A} / 2.5 \mathrm{X})$ \\
\hline $\begin{array}{l}\text { CH894 } \\
\text { Case } 7\end{array}$ & $\begin{array}{c}\text { M25167/ } \\
\text { 2012/aHUS }\end{array}$ & Yes & $\begin{array}{c}\text { Y backbone: csy disrupted by } \\
\text { insertion element }{ }^{30} \\
\text { [SAMN09011371] }\end{array}$ & 5774 (23) & $1.5-2,10-1$ & 1 Not found & p0007 (15X) & 25 (A/2.4X) \\
\hline $\begin{array}{l}\text { CH897 } \\
\text { Case } 8\end{array}$ & $\begin{array}{l}\text { M41546/ } \\
\text { 2012/PNH }\end{array}$ & Yes & $\begin{array}{l}\text { Y backbone: internal stop } \\
\text { in } \operatorname{css} A \text { [SAMN10701623] }\end{array}$ & $23(23)$ & $1.5-2,10-1$ & 1 Not found & p0007 (27X) & $25(\mathrm{~A} / 15 \mathrm{X})$ \\
\hline $\begin{array}{l}\text { CH878 } \\
\text { Case } 9\end{array}$ & $\begin{array}{l}\text { M36639/ } \\
\text { 2014/PNH }\end{array}$ & $\mathrm{No}^{\S}$ & $\begin{array}{c}\text { E backbone } c s e B \text { disrupted } \\
\text { by insertion element }{ }^{30} \\
\text { internal stop in } c s e G \\
\text { missing } s c e A \text { [SAMN09011504] }\end{array}$ & 1649 (1157) & $1.22,9$ & $\begin{array}{l}\text { Incomplete } \\
\text { ORF }\end{array}$ & p0010 (17X) & $13(\mathrm{~B} / 8.9 \mathrm{X})$ \\
\hline $\begin{array}{l}\text { CH892 } \\
\text { Case } 10\end{array}$ & $\begin{array}{l}\text { M38354/ } \\
\text { 2015/PNH }\end{array}$ & Yes & $\begin{array}{l}\text { B backbone: phase variable } \\
\text { OFF in csb [SAMN09011534] }\end{array}$ & $12476(41 / 44)$ & $1.18-1,34$ & Not found & p0002 (15X) & 19 (A/7.1X) \\
\hline $\begin{array}{l}\text { CH880 } \\
\text { Case } 11\end{array}$ & $\begin{array}{c}\text { M29686/ } \\
\text { 2015/aHUS }\end{array}$ & $\mathrm{No}^{8}$ & $\begin{array}{l}\text { C backbone, all essential } \\
\text { capsule genes intact } \\
\text { [SAMN10701620] }\end{array}$ & $35(35)$ & $1.22-1,14$ & Not found & p0021 (9.9X) & 16 (A/11X) \\
\hline $\begin{array}{l}\text { CH896 } \\
\text { Case } 13\end{array}$ & $\begin{array}{l}\text { M41198/ } \\
\text { 2016/PNH }\end{array}$ & Yes & $\begin{array}{l}\text { Null locus }(\mathrm{cnl}) \\
\text { [SAMN10701622] }\end{array}$ & $2578(41 / 44)$ & $1.17,9$ & Not found & p0002 (37X) & $100(\mathrm{~B} / 47 \mathrm{X})$ \\
\hline $\begin{array}{l}\text { CH891 } \\
\text { Case } 16\end{array}$ & $\begin{array}{l}\text { M41162/ } \\
\text { 2016/aHUS }\end{array}$ & Yes & $\begin{array}{c}\text { B backbone: } c t r A \text { truncated } \\
\text { internal stop in cssC } \\
\text { [SAMN10701621] }\end{array}$ & $409(41 / 44)$ & $1.18-1,34$ & Not found & p0002 (30X) & $19(\mathrm{~A} / 8.0 \mathrm{X})$ \\
\hline $\begin{array}{l}\text { CH900 } \\
\text { Case } 17\end{array}$ & $\begin{array}{l}\text { M45193/ } \\
\text { 2018/PNH }\end{array}$ & No & $\begin{array}{l}\text { Null locus }(\mathrm{cnl}) \\
\text { [SAMN10701624] }\end{array}$ & 34 (32) & $1.19,15$ & $1.1(10 \mathrm{X})$ & p0020 (23X) & 1 (B/37X) \\
\hline $\begin{array}{l}\text { CH901 } \\
\text { Case } 18\end{array}$ & $\begin{array}{l}\text { M47708/ } \\
\text { 2018/PNH }\end{array}$ & No & $\begin{array}{c}\text { E backbone: } \operatorname{cse} A \\
\text { disrupted by insertion } \\
\text { element } 1301, \text { internal } \\
\text { stops in } \operatorname{cse} B, \operatorname{cse} G ; \\
\text { missing } \operatorname{cse} A \text { [SAMN10701625] }\end{array}$ & 12475 (1157) & $1.22,9-13$ & $\begin{array}{l}\text { Incomplete } \\
\text { ORF }\end{array}$ & p0010 (13X) & $13(\mathrm{~B} / 29 \mathrm{X})$ \\
\hline \multicolumn{9}{|c|}{$\begin{array}{l}\text { 'Of } 17 \text { cases with clinical samples ( } \mathrm{n}=1 \text { ) or isolates ( } \mathrm{n}=16) \text { submitted to the Centers for Disease Control and Prevention (CDC), four isolates were confirmed to be serogroup } \\
\text { Y [ cases } 1 \text { (2008), } 5 \text { (2011), } 12 \text { (2015) and } 15 \text { (2017)] (Online Supplementary Table S1), and } 13 \text { were non-groupable (NG) including case } 14 \text { confirmed by polymerase chain } \\
\text { reaction of a clinical sample in the absence of an available isolate.The } 12 \mathrm{NG} \text { cases with available isolates are included in this table. SSerum bactericidal activity (SBA) was } \\
\text { not measured for four of the } 12 \text { available NG isolates (cases } 17 \text { and } 18 \text { reported to the CDC in 2018, and cases } 9 \text { and } 11 \text { because of auto-agglutination). *The whole genome } \\
\text { sequencing read data can be found under BioProject PRJNA513307 (https://www.ncbi.nlm.nih. gov/bioproject/PRJNA513307). 'MLST: multilocus sequence type; "PorA } \\
\text { variable region sequence type inferred from amino acid sequences of variable regions VR1 and VR2, respectively; NadA, Neisserial adhesin A; NHba (Neisserial heparin } \\
\text { binding antigen) and FHbp (factor H binding protein) identification numbers are described on the public website https://pubmlst.org/neisseria/ "Expression was meas- } \\
\text { ured by flow cytometry. Data are expressed as a ratio (X-fold) of binding with the specific antiserum to that of the negative control antiserum (Online Supplementary Figure } \\
\text { S2). All isolates had undetectable NadA (s1X-fold) except for CH900 (Online Supplementary Figure S2). PNH, paroxysmal nocturnal hemoglobinuria; NmO, neuromyelitis } \\
\text { optica; aHUS, atypical hemolytic uremic syndrome. }\end{array}$} \\
\hline
\end{tabular}




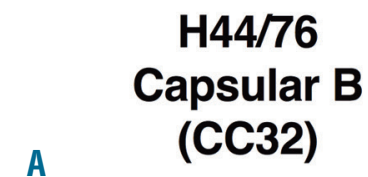

A

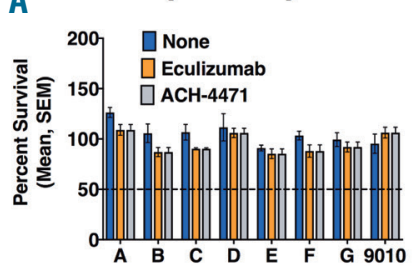

D

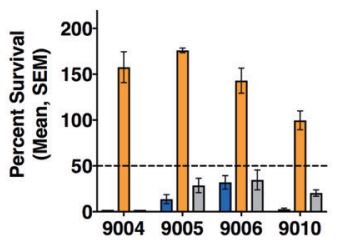

G

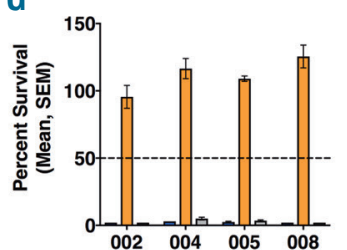

CH891, NG B Disrupted (CC41/44)

B

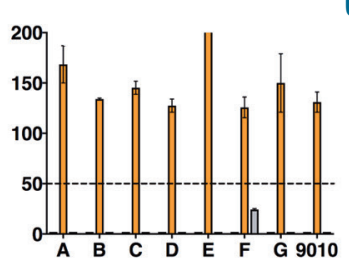

CH892, NG

B Phase Var. Off

(CC41/44)

C

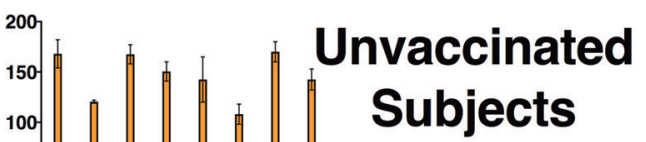

E

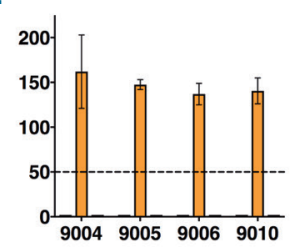

H

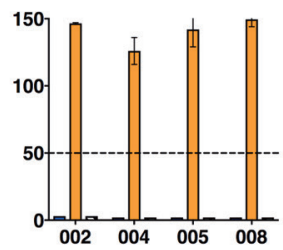

F

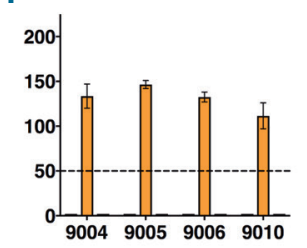

MenB-4C Vaccinated

I

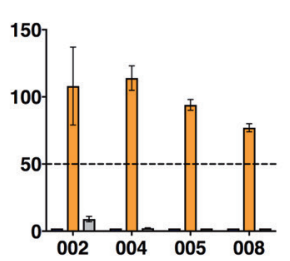

MenB-FHbp
Vaccinated

Figure 1. Effect of complement inhibitors on serum bactericidal activity measured against a control encapsulated serogroup B strain (H44/76) and two nongroupable isolates with disrupted or phase variable "off" B capsular loci. All sera were diluted 1:5 and assayed with internal (endogenous) complement. The horizontal line indicates $50 \%$ survival of bacteria after incubation for $60 \mathrm{~min}$. Sera with $<50 \%$ bacterial survival have serum bactericidal activity (SBA) titers $\geq 1: 5$. Blue bars, test sera with no added inhibitor; orange bars, test sera with $50 \mu \mathrm{g} / \mathrm{mL}$ eculizumab; gray bars, test sera with $1 \mu \mathrm{M}$ ACH-4471. (A-C) Adults not vaccinated with a serogroup B vaccine (subject 9010 represents a pre-immunization serum). (D-F) Adults vaccinated with MenB-4C (subject 9010 is a post-vaccination serum). (G-I) Adults vaccinated with MenB-FHbp. The encapsulated H44/76 strain [hypervirulent clonal complex (CC) 32] expressed FHbp sub-family B (present in both MenB vaccines). The non-groupable CH891 and CH892 isolates were both from CC41/44 and both expressed NHba (present in MenB-4C) and FHbp subfamily A (present in MenB-FHbp). Data for each isolate are from two to four replicates. NG: non-groupable; SEM: standard error of mean.

the concentration of $\mathrm{ACH}-4471$ to $0.5 \mu \mathrm{M}$ or $0.25 \mu \mathrm{M}$ resulted in less inhibition of SBA than did $1 \mu \mathrm{M}$ ACH4471 for two of the three vaccinated sera (Online Supplementary Figure S5B). However, even the lowest ACH-4471 concentration tested, $0.25 \mu \mathrm{M}$, completely inhibited SBA of the unvaccinated serum pool (Online Supplementary Figure S5B), highlighting the importance of the alternative pathway for SBA by unvaccinated sera.

While titers $\geq 1: 4$ with human complement are considered protective against developing meningococcal disease, ${ }^{12}$ titers $<1: 4$ do not necessarily imply susceptibility. ${ }^{13}$ We therefore tested a 1:2.5 dilution of the six unvaccinated and three vaccinated sera for which SBA at 1:5 dilution against isolate $\mathrm{CH} 886$ was inhibited by $1 \mu \mathrm{M}$ ACH4471. For this experiment we used $2 \mu \mathrm{M} \mathrm{ACH}-4471$ to maintain the same ratio of $\mathrm{ACH}-4471$ to internal complement. In the 1:2.5 dilution of sera from the six unvaccinated subjects, $2 \mu \mathrm{M}$ ACH-4471 still blocked SBA (Figure 2D). However, all three vaccinated subjects with SBA blocked with $1 \mu \mathrm{M}$ $\mathrm{ACH}-4471$ at a serum dilution of 1:5 had SBA at the 1:2.5 dilution in the presence of $2 \mu \mathrm{M} \mathrm{ACH}-4471(<50 \%$ bacterial survival) (Figure $2 \mathrm{E}$ ). This result suggests that the higher concentration of anti-meningococcal antibodies at the lower serum dilution was sufficient for SBA in the absence of alternative pathway amplification.
In the USA a large majority of cases of invasive meningococcal disease in immunocompetent people are caused by encapsulated serogroup B, C, W, or Y strains. ${ }^{3}$ A striking finding among the eculizumab-treated patients in this study was that $76 \%$ of the cases were caused by N

meningococci (Online Supplementary Table S1). NG meningococci are most commonly commensals of the nasopharyn $\mathrm{x}^{14}$ and rarely cause invasive disease. In the present investigation, seven of the eight NG isolates tested were killed by sera from all eight unvaccinated adults, suggesting that these NG isolates would be unlikely to cause invasive disease in immunocompetent adults regardless of meningococcal vaccination status.

When serum anti-meningococcal antibody titers are high, SBA can occur via the classical pathway alone (Online Supplementary Figure S1). The alternative pathway is needed primarily when the amount of classical pathway activation does not elicit sufficient $\mathrm{C} 3 \mathrm{~b}$ deposition on the bacteria to form a functional membrane attack complex. ${ }^{15}$ Our results suggest that vaccine-induced serum antibody levels were sufficient for SBA by the classical pathway alone for the six of the eight test isolates for which SBA in vaccinated sera was not inhibited by $\mathrm{ACH}-4471$. The remaining two NG isolates required the alternative pathway for SBA in sera from one to three 


\section{CH886, NG, E Disrupted (CC60) Unvaccinated}

A

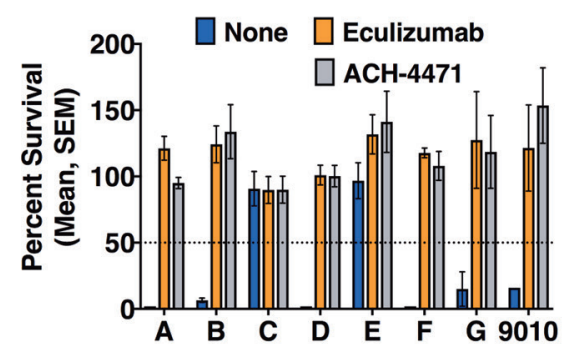

D

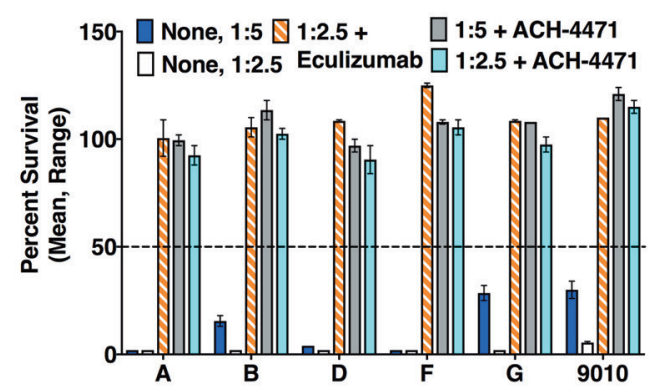

B

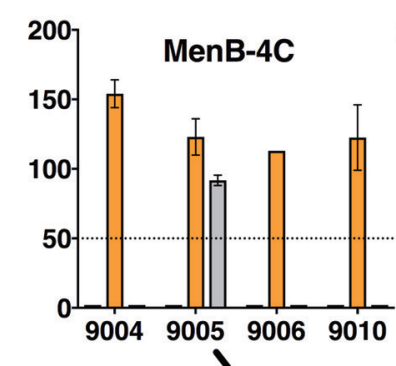

E

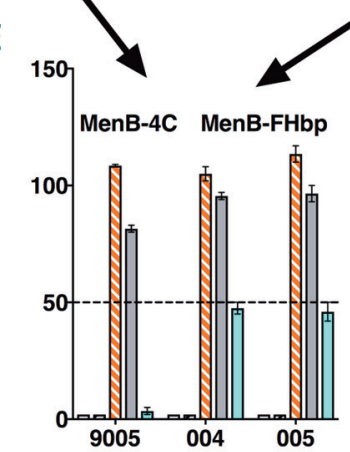

MenB-FHbp

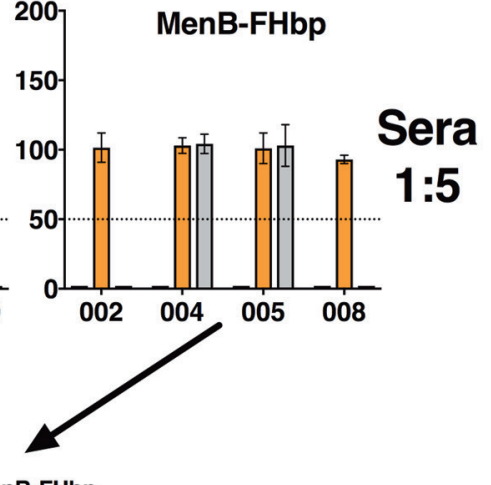

Figure 2. Effect of complement inhibitors on serum bactericidal activity measured against non-groupable isolate $\mathrm{CH} 886$ with $\mathrm{CC} 60$ and a disrupted $\mathrm{E}$ capsular locus. (A-E) Without added inhibitor, two of eight unvaccinated subjects (subjects $\mathrm{C}$ and $\mathrm{E}$ ) had titers $<1: 5$ (bacterial survival $>50 \%$ after $1 \mathrm{~h}$ incubation) (blue bars in panel A) compared to none of eight vaccinated subjects (blue bars in panels $B$ and $C$ ). (D,E) Among the six unvaccinated subjects with titers $\geq 1: 5$ without inhibitor, serum bactericidal activity (SBA) at 1:5 dilution was inhibited (bacterial survival $>50 \%$ ) by $1 \mu \mathrm{M} \mathrm{ACH}-4471$ (gray bars in panels A and D) or at a 1:2.5 serum dilution by $2 \mu \mathrm{M} \mathrm{ACH}-4471$ (teal bars in panel D). Among the eight vaccinated subjects, the addition of $1 \mu \mathrm{M}$ ACH-4471 inhibited SBA at a dilution of 1:5 for three of eight vaccinated subjects (black bars in panels B and C; gray bars in panel E) but all three sera had SBA when retested at a 1:2.5 dilution in the presence of $2 \mu \mathrm{M} \mathrm{ACH}-4471$ (bacterial surival $<50 \%$; teal bars in panel E). With eculizumab, SBA titers were $<1: 5$ or $<1: 2.5$ for all unvaccinated or vaccinated sera tested at both dilutions (bacterial survival $>50 \%$, orange bars). (A-C) Data from two to four replicate assays using $50 \mu \mathrm{g} / \mathrm{mL}$ of eculizumab and $1 \mu \mathrm{M}$ ACH4471. (D, E) Data are representative of two assays, each performed in duplicate with $1 \mu \mathrm{M} \mathrm{ACH}-4471$ for sera tested at 1:5, $2 \mu \mathrm{M}$ ACH-4471 for sera tested at 1:2.5 (see text), and $50 \mu \mathrm{g} / \mathrm{mL}$ of eculizumab for sera assayed at 1:2.5. NG: non-groupable; SEM: standard error of mean.

vaccinated donors (Online Supplementary Table S2).

Protection against meningococcal disease may also be conferred by opsonophagocytic bacterial killing, ${ }^{16}$ which does not require an intact terminal complement pathway (Online Supplementary Figure S1). In previous studies, however, inhibiting cleavage of C5 to C5a and C5b by eculizumab, and thereby inhibiting both the terminal complement pathway and release of the pro-inflammatory peptide $\mathrm{C} 5 \mathrm{a}$, completely blocked whole blood opsonophagocytic/bactericidal activity of encapsulated serogroup $\mathrm{B}$ or $\mathrm{C}$ meningococcal strains. ${ }^{5}$ In contrast, when the terminal complement pathway was blocked at C7, which did not affect C5a release, SBA was blocked but opsonophagocytic killing was minimally or not inhibited. ${ }^{2,5}$

Our results with NG strains from patients treated with eculizumab who developed meningococcal disease, along with our previously published data regarding encapsulated strains, ${ }^{5}$ suggest that therapeutic agents that selectively block the alternative pathway would be expected to result in less impairment of immunity to meningococcal disease than does eculizumab, particularly after meningococcal vaccination. The highest likelihood of meningococcal disease among recipients of alternative pathway inhibitors would be expected when serum antibody titers wane and the alternative pathway is required for classical pathway amplification to achieve SBA and/or opsonophagocytic activity (amplification loop, Online Supplementary Figure S1). Thus, it will be important to monitor patients receiving alternative pathway inhibitors during clinical trials and after licensure to ensure that these patients are optimally protected from meningococcal disease.

Dan M. Granoff,' Howard Kim, ${ }^{1}$ Nadav Topaz, ${ }^{2}$ Jessica MacNeil, Xin Wang and Lucy A. McNamara ${ }^{2}$

${ }^{1}$ Center for Immunobiology and Vaccine Development, UCSF Benioff Children's Hospital Oakland, Oakland, CA, and 'Meningitis and Vaccine Preventable Diseases Branch, Division of Bacterial Diseases, National Center for Immunization and Respiratory Diseases, Centers for Disease Control and Prevention, Atlanta, GA, USA

Funding: this investigation was supported by research grants R01 AI046464 and R01 AI114701 from the National Institute of Allergy and Infectious Diseases, National Institutes of Health (NIH). The flow cytometry and SBA were performed in a facility funded by the Research Facilities Improvement Program grant C06 RR016226 from the National Center for Research Resources, NIH.

Acknowledgmemts: we are grateful to Achillion Pharmaceutical, Inc. for providing ACH-4471, and to Drs. Mingjun Huang, Steven Podos and Manuel Galvan, Achillion Pharmaceutical, Inc., New Haven CT, USA and Sanjay Ram, University of Massachusetts Medical School, Worcester, MA, USA for critical review of the manuscript. We thank 
Lorraine R. Rodriguez, Melissa Whaley, Karen Anderson, and David Lonsway from the Centers for Disease Control and Prevention for assistance with antimicrobial susceptibility testing. The findings and conclusions in this report are those of the authors and do not necessarily represent the official position of the Centers for Disease Control and Prevention (CDC).

Correspondence: DAN M. GRANOFF.

dgranoff@chori.org

doi:10.3324/haematol.2018.209692

Information on authorship, contributions, and financial \& other disclosures was provided by the authors and is available with the online version of this article at www. haematologica.org.

\section{References}

1. McNamara LA, Topaz N, Wang X, et al. High risk for invasive meningococcal disease among patients receiving eculizumab (Soliris) despite receipt of meningococcal vaccine. MMWR Morb Mortal Wkly Rep. 2017;66(27):734-737.

2. Nolfi-Donegan D, Konar M, Vianzon V, et al. Fatal nongroupable Neisseria meningitidis disease in vaccinated patient receiving eculizumab. Emerg Infect Dis. 2018;24(8):1561-1564.

3. MacNeil JR, Blain AE, Wang X, Cohn AC. Current epidemiology and trends in meningococcal disease-United States, 1996-2015. Clin Infect Dis. 2018;66(8):1276-1281

4. Yuan X, Gavriilaki E, Thanassi JA, et al. Small-molecule factor D inhibitors selectively block the alternative pathway of complement in paroxysmal nocturnal hemoglobinuria and atypical hemolytic uremic syndrome. Haematologica. 2017;102(3):466-475.

5. Konar M, Granoff DM. Eculizumab treatment and impaired opsonophagocytic killing of meningococci by whole blood from immunized adults. Blood. 2017;130(7):891-899.

6. Performance Standards for Antimicrobial Susceptibility Testing. 27th edition Clinical Laboratory Standards Institute (CLSI) supplement M100. Wayne, PA USA: Clinical and Laboratory Standards Institute, 2017.
7. Harrison $\mathrm{OB}$, Claus $\mathrm{H}$, Jiang $\mathrm{Y}$, et al. Description and nomenclature of Neisseria meningitidis capsule locus. Emerg Infect Dis. 2013;19(4):566-573.

8. Folaranmi T, Rubin L, Martin SW, et al. Use of serogroup B meningococcal vaccines in persons aged $\geq 10$ years at increased risk for serogroup B meningococcal disease: recommendations of the advisory committee on immunization practices, 2015. MMWR Morb Mortal Wkly Rep. 2015;64(22):608-612.

9. Giuntini S, Pajon R, Ram S, Granoff DM. Binding of complement factor $\mathrm{H}$ to PorB3 and NspA enhances resistance of Neisseria meningitidis to anti-factor $\mathrm{H}$ binding protein bactericidal activity. Infect Immun. 2015;83(4):1536-1545.

10. Giuntini S, Lujan E, Gibani MM, et al. Serum bactericidal antibody responses of adults immunized with the MenB- $4 \mathrm{C}$ vaccine against genetically diverse serogroup $\mathrm{B}$ meningococci. Clin Vaccine Immunol. 2017;24(1).

11. Lujan E, Partridge E, Giuntini S, Ram S, Granoff DM. Breadth and duration of meningococcal serum bactericidal activity in healthcare workers and microbiologists immunized with the MenB-FHbp vaccine. Clin Vac Immunol. 2017;24e(8).

12. Borrow R, Carlone GM, Rosenstein N, et al. Neisseria meningitidis group $\mathrm{B}$ correlates of protection and assay standardization--international meeting report Emory University, Atlanta, Georgia, United States, 16-17 March 2005. Vaccine. 2006;24(24):5093-5107.

13. Welsch JA, Granoff D. Immunity to Neisseria meningitidis group $B$ in adults despite lack of serum bactericidal activity. Clin Vaccine Immunol. 2007;14:1596-602.

14. Harrison LH, Shutt KA, Arnold KE, et al. Meningococcal carriage among Georgia and Maryland high school students. J Infect Dis. 2015;211(11):1761-1768

15. Welsch JA, Ram S, Koeberling O, Granoff DM. Complement-dependent synergistic bactericidal activity of antibodies against factor $\mathrm{H}$ binding protein, a sparsely distributed meningococcal vaccine antigen. J Infect Dis. 2008;197(7):1053-1061

16. Granoff DM. Relative importance of complement-mediated bactericidal and opsonic activity for protection against meningococcal disease. Vaccine. 2009;27(Suppl 2):B117-B125. 